\title{
ESTIMATING CARBON AND GREENHOUSE GAS EMISSIONS IN REMOTE REGIONS OF CANADA
}

\author{
I. Ituen ${ }^{1}, \mathrm{~B} . \mathrm{Hu}^{*} 1$ \\ ${ }^{1}$ Department of Earth \& Space Science \& Engineering, York University, Toronto, Canada - (iituen, baoxin)@ yorku.ca
}

KEY WORDS: MODIS, land use/landcover, change detection, carbon calculation, carbon models

\begin{abstract}
:
Longer growing seasons in Northern Ontario are predicted, as a result of climate change. There is the expectation that there will be increased land use conversion from natural forests in Northern Ontario to capitalise on the new economic opportunities resulting from longer growing seasons. This study examines the impacts the land conversion - from forest to agricultural environment - has on the greenhouse gas emissions and soil properties. We use remote sensing technologies for detecting these changes. This paper highlights an automatic method we developed for change detection. The method was applied to the satellite data over a predominantly vegetated area of Northern Ontario for the period 2001 to 2016. The study showed how the forest air and soil properties transform over time from various land disturbances, and how subsequent management schemes affect the environmental properties such as greenhouse gas emissions and the soil carbon stock.
\end{abstract}

\section{INTRODUCTION}

Many times, a change in landcover is accompanied by a change in land use. Between 2007 and 2016, the total emissions from forestry and other land use change (e.g. afforestation, deforestation, wood harvest, peatland burning) amounted to 5.2 ( \pm 2.6$) \mathrm{Gt} \mathrm{CO}_{2}$ per yr (IPCC 2019). Deforestation - the clearing of a forest for agricultural purposes - has an impact on the carbon budgets. Similarly, afforestation will cause an increase in the local carbon uptake in that area. Agricultural land use changes have been known to impact health, the environment, and local climate (Hulley et al., 2014). Land conversion from forest to cropland can also reduce the soil's quality and carbon (BatlleAguilar et al., 2011). Batlle-Aguilar et al. (2011) observed that in the first 10 years of having been converted from forest to cropland, the total soil carbon decreases by up to $30 \%$, depending on other influences such as the climate, type of soil, the crop planted, and the crop management practices. When forest is converted to pasture, it has been found that the ammonium (NH4) increases in the pasture lands (Batlle-Aguilar et al., 2011). Similarly, the impact on soil organic carbon from land use changing from cropland to forest has been well documented in literature (Veldkamp E., 1994; de Moraes et al, 1996). For instance, one study indicated the soil carbon increased up to $20 \%$ in the twenty years following the land use conversion (de Moraes et al., 1996) while another quoted has seen reduction of up to $18 \%$ in the twenty-five years.

Carbon in its various forms (e.g. $\mathrm{CO}, \mathrm{CO}_{2}$ ) comes from sources such as anthropogenic activities - burning fossil fuels, cement, farming, and land use change - and the natural carbon cycle from respiration and decomposition of matter. On land, carbon stock comes from biomass (living organisms in forest) and dead organic matter is comprised of woody debris, the forest floor, and soil.

The greenhouse gases related to agriculture are nitrous oxide $\left(\mathrm{N}_{2} \mathrm{O}\right)$, methane $\left(\mathrm{CH}_{4}\right)$, and carbon dioxide $\left(\mathrm{CO}_{2}\right) . \mathrm{N}_{2} \mathrm{O}$ enters soils after fertilizer is applied. Changes occur to the soil nutrient cycles after a harvest (Webster et al., 2015). The aim of this research is to estimate the carbon in soil as well as the final forest products, and thereby estimate the resulting greenhouse gas effect. For the study, carbon amounts in the forests will be calculated not only up to the point of harvest, but also afterwards: Lemprière et al. (2013) noted that calculations of carbon and the mitigation potential would be incorrect if analyses assume that no carbon is emitted at harvest, or that the products created from the harvested wood are carbon neutral. The Intergovernmental Panel on Climate Change (IPCC) mentions the five carbon pools which are to be measured and monitored for good practice: aboveground biomass, belowground biomass, litter, deadwood, and soil organic carbon (IPCC, 2003). These pools will be considered in this study.

A large-scale study was performed to estimate the changes in woody carbon stock in the entire cropland of Canada over the period of a decade (Huffman et al., 2015). Having considered the landcover changes for the various land types, such as forest, shrub, wetland, cropland, and settlement during the decade, the differences in woody carbon stock were calculated. The results indicated that the amounts varied by ecozone, e.g. the Mixedwood Plains and Boreal Plains showed an increase of $84.8 \mathrm{Gg} /$ year and $16.8 \mathrm{Gg} /$ year respectively, while the Prairie Parkland and Niagara region ecozones respectively had a decrease of $54.8 \mathrm{Gg} /$ year and $5.3 \mathrm{Gg} /$ year of carbon (Huffman et al., 2015). These results demonstrate the impact of landcover type on the carbon stock. Another study in Canada estimated the above- and below-ground organic carbon, differentiating the amounts from coniferous and deciduous trees (Tremblay and Ouimet, 2013). These studies have been successful and contributed greatly to the knowledge of the differences in the various ecozones of Canada. Yet to our knowledge, an in-depth look at the effect of climate change and the resulting carbon dynamics in the rich area of the Clay Belt has not been done. Our objective is to examine the effects on carbon stocks from different land management schemes. Specifically, by considering the carbon change from 20 years ago with the factors which led to those emissions, we will predict how much soil and atmospheric carbon will be present 20 years from now, if similar land changes and disturbances occur again as did historically.

\footnotetext{
* Corresponding author
} 
In recent years, the area under study has seen longer than normal growing seasons due to climate changes. It is anticipated that the warmer weather will produce more economic opportunities for farmers and loggers alike, and result in an increase in land use changes. With the different activities which will occur, there will be greenhouse gas emissions (GHG) and stored organic carbon will be displaced. This study highlights a novel approach to identifying landcover change using remotely sensed data. It also examines preliminary results of assessing the amounts of soil organic carbon and GHG's from the landcover changes which occur in the region.

\section{STUDY AREA}

The study area is Ontario's Great Clay Belt region, in northeast Ontario, Canada. This region spans 120,000 sq. km, is centred at $49.476 \mathrm{~N},-82.283 \mathrm{~W}$, and extends between $48.5 \mathrm{~N}$ and $50.0 \mathrm{~N}$. Ontario's Clay Belt is heavily forested and has several lakes within it. The predominant landcover types are shrubland, wetland, water, agricultural land, coniferous-, deciduous-, and mixed-treed covers. Specifically, the tree species most abundant in the region are the balsam fir, black spruce, eastern larch, white spruce, trembling aspen, and balsam poplar. The region is dubbed the 'Great Clay Belt' because most of the soils consists of heavy and rich clay loam. There are various soil types in the Clay Belt such as Gray luvisolic, Gleysolic, Podzolic, and organic mesisols. Apart from livestock farming such as beef and dairy cows, there exists an extensive agricultural industry with farms of barley, oat, and wheat crops. Commercial tree harvesting is also conducted, taking advantage of the large, quality trees in this boreal forest region.

With the warming effects of climate change (OMAFRA, 2017), it is expected that there will be even more clearing of forests as they are converted to agricultural land. The Ontario Ministry of Agriculture, Food, and Rural Affairs (OMAFRA) has recognised this as an opportunity for developing the Great Clay Belt area. They have developed an initiative to convert some of the forested land to agriculture land. The name of the program is tagged the Northern Livestock Pilot Project. An area of the Clay Belt has been delineated for this pilot project. The sites are mainly forested, with $76 \%$ of the area being treed $(60 \%$ tall treed, and $16 \%$ low treed), and roughly $14 \%$ being shrubland. The average crown closure is $68 \%$, the average tree age is 73 years, and the predominant tree types are black spruce, trembling aspen, eastern larch, and balsam poplar.

\section{MODELLING CHANGE AND MODELLING CARBON}

\subsection{Land Use and Land Cover Change Detection}

In this study, a multi-scale change detection method was developed to detect the change in land cover and land use in the Great Clay Belt area for the past several decades. To minimize the computation complexity, a change detection with a binary output (change and no-change) was carried out first at the regional scale using Moderate Resolution Imaging Spectroradiometer (MODIS) data. A detailed change assessment was then conducted on the areas of change previously identified. For the first stage, we developed a fully automatic change detection method based on the Land Surface Temperature (LST) and Normalised Difference Vegetation Index (NDVI) (Ituen, Hu, 2021).
Following image pre-processing geometric and radiometric corrections, a Gaussian filter was applied to smooth out any noise in the data. Then image segmentation - creating clusters of homogenous areas known as superpixels - was performed. Superpixels were used as the basic unit of analysis. By performing a statistical $\mathrm{T}^{2}$ test on the feature vectors of NDVI and LST, it could be determined if significant change had occurred in the region. Our new approach for detecting landcover change achieved accuracies ranged between $78 \%$ and $88 \%$ for the NDVIbased test, and from $74 \%$ to $86 \%$ for the LST-based test, compared with manual interpretation. This was consistent with similar studies of landcover change detection using MODIS data (Ituen, $\mathrm{Hu}, 2021$ ).

For the areas with changes detected, classification using multisource remotely sensed data was carried out for the years involved. When it comes to landcover/land use change analysis for the purpose of carbon accounting, usually post-classification methods are used. This is so that the carbon amounts can be estimated since the amounts will vary based on the land use type. For example, Seyum et al. (2019) performed land use classification in order to determine the soil carbon stock in three different decades. Using Google Earth and GPS from fieldwork for verification, this study had a land use classification accuracy of $87 \%$ (Seyum et al., 2019).

Sharma et al. (2019) also conducted a long-term change analysis study, examining the change in soil carbon stock over the period of two decades. Again, the land use dynamics was analysed following the supervised maximum likelihood classification of Landsat images over the study area. Some of the land use categories were forest, scrubland, agricultural cropland, agricultural plantation, water body, settlement, and wasteland. The overall accuracy from the classification method ranged from 87.8 to $95.4 \%$. Sleeter et al. (2018) also used Landsat data as input for the land use/landcover classification performed to estimate carbon dynamics in their study area - the conterminous United States. Six land use types were identified: forest, grassland, shrubland, agriculture, developed, and wetland. the That study employed the Land Use and Carbon Simulator (LUCAS) to estimate the land use changes and carbon dynamics for each of the six ecoregions.

We also performed supervised classification to perform landcover on higher resolution satellite imagery. Some of the classes were bare earth, agricultural land, and forest.

\subsection{Carbon and Greenhouse Gas Calculation Methods}

In this study, the Carbon Budget Model of the Canadian Forest Sector (CBM-CFS3) was used for carbon and GHG estimations in forest and shrubland. CBM is commonly used for assessing carbon stocks and forecasting (Kurz et al., 2009). Although developed in Canada, it is widely used in other countries for their carbon accounting and reporting to regulatory bodies such as IPCC. The CBM does not currently account for all transitions from forested to non-forested land. Thus, we use the CArbon and Nitrogen DYnamics (CANDY) model for carbon dynamics in conversion from forest to agricultural land. The CANDY model is usually used to calculate the short-term dynamics of nitrogen transformation as well as the accumulation of carbon in cropland. It has also been used successfully to estimate carbon flux in the long-term (Franko et al., 1997). This present paper presents the portion of work done using the CBM model.

The CBM modeller has a two-fold usage in this work: a) to monitor past carbon stocks and stock changes; $b$ ) to project the future carbon stocks and stock changes so as to assess the forest 
management options. Table 1 below shows some of the inputs and outputs of the model.

Table 1. Sampling of inputs and outputs from CBM model
\begin{tabular}{|l|l|}
\hline CBM Model Inputs & \multicolumn{1}{c|}{ CBM Model Outputs } \\
\hline Forest inventory & Soil carbon stock \\
\hline $\begin{array}{l}\text { Growth-and-yield } \\
\text { curves }\end{array}$ & $\begin{array}{l}\text { Carbon stock changes (DOM \& } \\
\text { biomass) }\end{array}$ \\
\hline Disturbance history & $\begin{array}{l}\text { Ecosystem carbon transfers to the } \\
\text { atmosphere }\end{array}$ \\
\hline Disturbance forecast & GHG emissions $\left(\mathrm{CO}_{2}, \mathrm{CO}, \mathrm{CH}_{4}\right)$ \\
\hline Climate data & $\begin{array}{l}\text { Transfers from hardwood harvest \& } \\
\text { softwood harvest (biomass) to the } \\
\text { soil }\end{array}$ \\
\hline Land use changes & $\begin{array}{l}\text { Above- and below-ground carbon in } \\
\text { DOM }\end{array}$ \\
\hline Harvest schedule & $\begin{array}{l}\text { Ecosystem losses of carbon due to: } \\
\text { decomposition; harvesting; } \\
\text { disturbances }\end{array}$ \\
\hline
\end{tabular}

We used the growth and yield curves to simulate the merchantable volume of wood each tree species has over the course of the simulation. These tree growth curves were mainly obtained from provincial sources, as the growth curves vary by province. We also simulated competition in our models by adding a growth retardation factor in areas of mixed stands.

Other inputs we used for analysis include land-use classification changes, disturbances (e.g. fire, insect, deforestation, harvest impacts, forest disease), and stand age.

Among the numerous outputs obtainable from processing done with the CBM tool are: carbon stocks and fluxes, annual carbon transfers between pools (such as the dead organic matter pools consisting of aboveground and below ground dead tree biomass), GHG emissions to the atmosphere, transfers and emissions associated with disturbance types, and annual carbon stock change for the total ecosystem. These outputs are then used in various ways, e.g. for "carbon budgeting."

The CBM has a large database that contains information on ecosystem types, their area, and carbon contents. It also has input data files defining stand level disturbance impacts, climatic conditions, and stand growth dynamics. So, with the tool, we can simulate the changes in ecosystem pools, and the associated carbon fluxes. The model simulates forest growth and decomposition, disturbances, and the planting and regrowth of forests after disturbances. CBM has volume-to-biomass conversion parameters within it. These are maintained by the Canadian Forestry Centre, which hosts and manages the CBM tool. An assumption that can be made are the effects of competition, so a growth multiplier can be input in the model to either stunt or accelerate growth of a specie. Climate assumption can also be included, e.g. from a stable temperature to an increased temperature profile during the simulation period The model is representative of Canadian forests, with data representing 10 of Canada's 12 ecozones that contain forests (Kurz et al., 2009). Other common tools for estimating soil carbon dynamics include CENTURY, FORCARB, FORECAST, and Roth-C.

Modelling using CBM follows three distinct segments: preprocessing, processing, and post-processing. The post-processing entails viewing the results obtained, assessing them, and interpreting them accordingly. The processing portion is the simulation performed by the tool based on the definitions introduced to it. The pre-processing involves importing the data for the stands being studied.

Several input parameters were required for running the CBM model. Some of the inputs we used are as follows: First, we input the historical data such as original state of the land (or initial state from the beginning of the period to be simulated), vegetation species, disturbance history, soil types, and disturbance forecasts. We also defined the growth and yield curves for the trees in the study area. Now, these curves can be obtained from a multitude of sources such as Plonski's Normal Yield tables. Some growth curves are generic to the specie. However, for our study, we aimed to obtain growth curve data that was specific to our province. e.g. the growth curve for red pine in Alberta, a province in western Canada, could be different from that in Ontario, which is in central Canada.

For forested land, we input the number of stands and the specie types in each stand. In sequences where we modelled afforestation, we had to define the pre-forest landcover types and the prior agricultural practices.

Another parameter set were the transition rules for what occurs after a land disturbance event. For example, if a stand was $100 \%$ spruce before a wildfire event, we could model the stands to become $20 \%$ fir, $30 \%$ spruce, and $50 \%$ aspen after the fire.

We simulated both types of disturbances - natural and anthropogenic, such as tree logging. Thereby, we are able to compare the difference between a baseline (a natural forest which remains undisturbed for 20 years) and the carbon flux from a forest which has undergone anthropogenic activities. Wildfires of various intensity are known to occur within the Great Clay Belt area (Ahmed et al., 2017). The historical data for the disturbances like fire and insect damage are important not only to accurately characterise past carbon dynamics, but also to use to generate trends in order to predict the future disturbances which could occur in the study region. The CBM tool allows a user to schedule disturbance events. The disturbances can be simulated to occur over the entire study area or can be limited to certain stands. Then, the post-disturbance cover type can be defined, as specified by the transition rules.

Some uncertainties associated with the CBM-CFS3 model include data uncertainties, and those introduced by missing processes. The data uncertainties could arise from input data, for instance forest inventory, disturbance events, forest transitions which occurred, and even the growth and yield curves. In this study, we obtained data from reputable sources such as federal and provincial governmental agencies, and also consulted various sources, to mitigate data uncertainties. The uncertainties which arise from omitted ecological processes include extraordinary weather events which may have caused an increase or decrease in productivity, productivity enhancement factors such as fertilization or climate change, and even factors affecting the soil such as droughts or floods.

\section{RESULTS AND ANALYSIS}

One of the hindrances to measuring and monitoring forest carbon is the lack of data. For instance, some regions do not have historical data on forest changes, and limited remotely sensed data. Furthermore, the records on historical forest disturbances are sometimes unavailable or sparse in detail. Another challenge is the integration of field data and satellite data. Site-specific attributes of the area under study might be collected to supplement remotely sensed data. Field surveys are a very important aspect of monitoring carbon and GHG changes, yet questions remain on how best to merge the two data sources.

Using the trends of the disturbances in Ontario's Clay Belt region from insect infestation, wildfires, and logging, etc. we used the 
$\mathrm{CBM}$ to assess how the disturbances and land use changes affect the ecosystem carbon amounts. If these trends are modelled to observe their carbon production impact, proper or different management practices can be proposed to reduce net total ecosystem carbon. Some simulations we did are described here: In the first scenario, we simulated a 10-hectare area which had been an agricultural field for 50 years and was now being converted to forest of Coniferous and Deciduous stands. Thus, the area had undergone land use change. We also simulated disturbances which normally occur in the Clay Belt: we predicted $50 \%$ commercial thinning at 25 years, and partial cutting of the trees after 50 years. We also estimated the life of the trees to be 100 years. With these land management sequences, the results of the simulation are presented in Fig. 2. They show the carbon stock below ground, above ground, and total ecosystem carbon. The dead organic matter (DOM) is typically from litter fall and dead trees, the matter considered below the ground. It is found in roots, snags, and stumps. Biomass on the other hand is counted as the living organic matter above ground such as in merchantable stems, foliage, barks, branches.

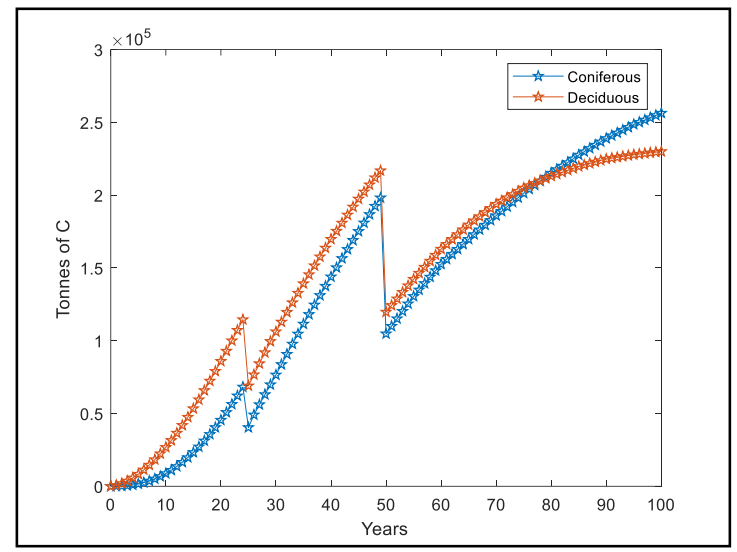

(a)

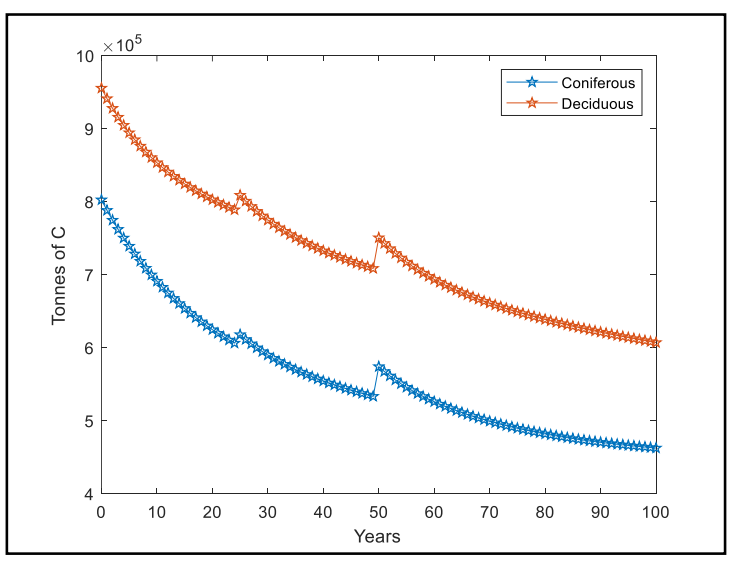

(b)

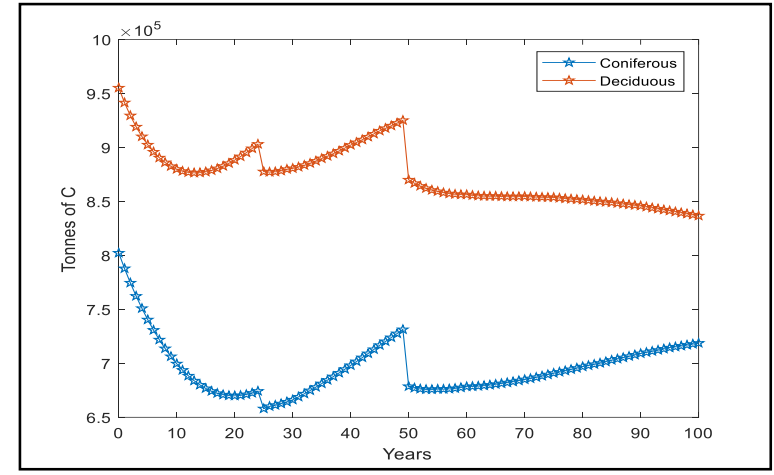

(c)

Figure 1: (a) Biomass pool; (b) DOM pool; and (c) Total Ecosystem carbon pool for a two-stand area

Figure 1 shows that the cutting of trees reduces the system's carbon for a while but then as the trees continue to grow, more carbon is produced until they probably reach carbon equilibrium. It can also be seen that both tree classes generate high carbon stocks after disturbance. The deciduous trees maintain a higher DOM stock, resulting in higher total ecosystem carbon stock.

For another simulation, we used trees which are predominant in the study area: Balsam poplar, Eastern Larch, Black spruce, Trembling aspen. Since there are several forests in the Great Clay Belt area which are commercially logged, we stipulated in this scenario that the trees would be regularly harvested for timber. Different disturbances were introduced to the various stands at year 25 , though a wildfire which affected all the stands was simulated to occur in year 0 . The unique disturbances for the species were clear cutting followed by burning, insect disturbance (spruce beetle which affected $20 \%$ of the stands), and fire with salvage of the wood. Another wildfire incident covering all the tree species was introduced at 75 years. Figure 2 below shows some of the results obtained.

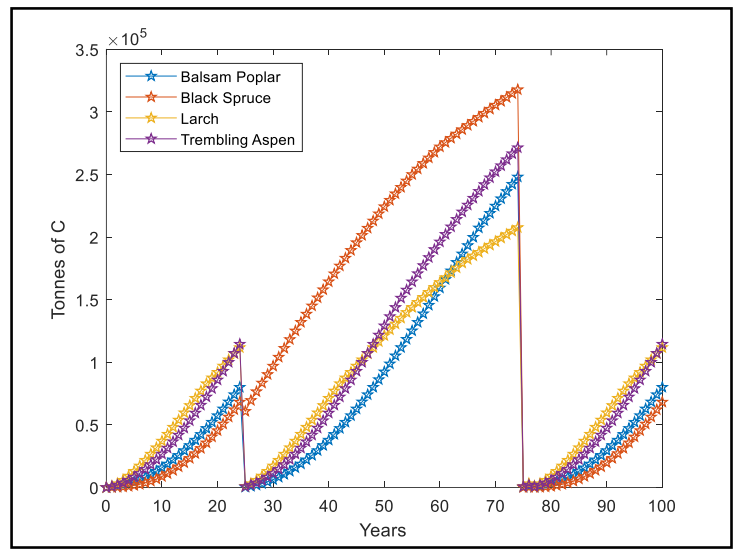

(a) 


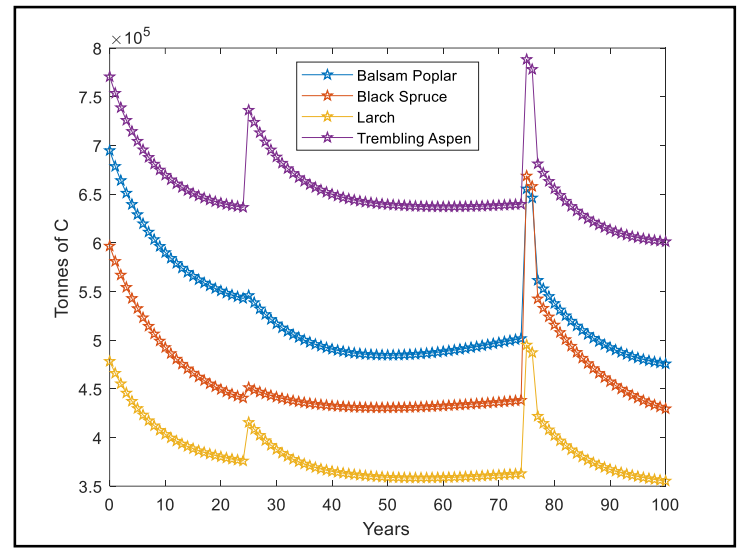

(b)

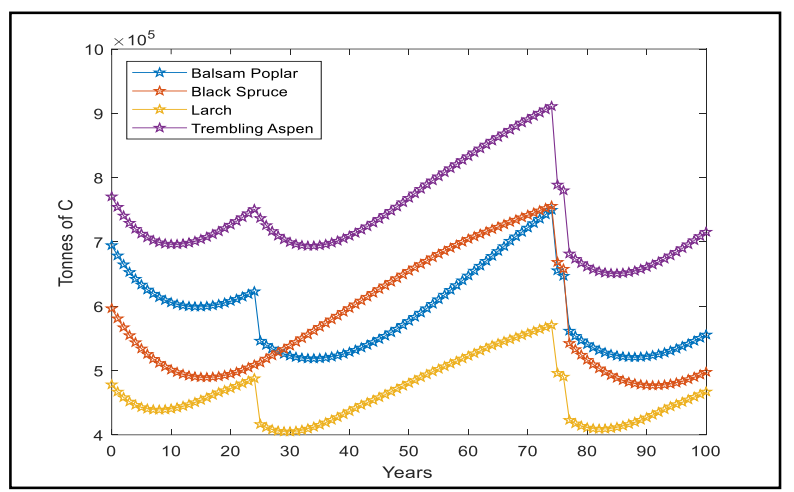

(c)

Figure 2: (a) Biomass pool; (b) DOM pool; and (c) Total Ecosystem carbon pool for a four-stand area

As seen in Figure 2, the different stands respond differently to disturbance. Where the Larch had fire and salvage in year 25 and the trembling aspen had insect disturbance, they both dramatically lost biomass in year 25 from the disturbance yet the larch remained with less carbon overall than the aspen. Furthermore, spruce and aspen had the highest biomass after the insect attack. The balsam poplar had high stock in the DOM pool, though low biomass. Also observed from the simulation was that the trembling aspen and balsam poplar were the species which acted as a carbon sink for the most number of years over the course of the simulation.

Differences also existed with the soil types: Luvisolic has the lowest dead organic matter carbon value. Meanwhile, Brunisolic non-forest soil type has the highest initial carbon value and so ends up with the highest dead organic matter (DOM) carbon content in the simulation period.

Some noted results include: Spruce and aspen have the highest biomass after the insect attack. The Balsam poplar has high stock in DOM pool, though low biomass. And trembling aspen and balsam poplar are the best carbon sinks (Figure 2). These simulations demonstrate the impact of agricultural expansion in northern Ontario on soil carbon stocks and GHG emissions.

\section{CONCLUSIONS}

One of the most common forms of land use change is the conversion of forested to agricultural land. Of great interest is whether a forest is acting as a carbon sink or a carbon source, or if it is even carbon neutral. The carbon balance of the forest is dependent on factors such as historical disturbances, the current tree growing conditions and disturbance patterns, and the forest management practices.

This study examines changes in landcover in the Clay Belt area for the purpose of estimating the resulting flux in soil organic carbon and GHG's which arose from the changes. A novel method of detecting change has been presented. Using the trends of the disturbances in that region, from insect infestation, to wildfires, and logging, etc. we used the CBM tool to assess how the disturbances and land use changes affect the ecosystem carbon amounts. If these trends are modelled to observe their carbon production impact, proper or different management practices can be proposed to reduce net total ecosystem carbon. Some of the simulation results generated from the CBM tool based on data inputs were presented. They illustrate that disturbances and landcover change play a role in ecosystem emissions and carbon sequestration.

Further studies will be done in the validation of the carbon and GHG calculations. It is a well-known problem, the lack of reliable or quality ground reference data to validate remotely sensed images (White et al., 2011). As efforts continue in this regard, the estimations done in this study will be more representative of the Great Clay Belt region. Presently, simulations as done here demonstrate the impact agricultural expansion in Northern Ontario will have on soil carbon stocks and GHG emissions.

\section{ACKNOWLEDGEMENTS}

The authors would gratefully like to acknowledge the support of NRCan, OMAFRA, Agriculture and Agri-Food Canada, Enbridge, and NSERC for this work.

\section{REFERENCES}

Ahmed, O. S., Wulder, M. A., White, J. C., Hermosilla, T., Coops, N. C., \& Franklin, S. E. (2016). Classification of ANNUAL non-stand REPLACING boreal FOREST change in Canada USING landsat time SERIES: A case study in northern Ontario. Remote Sensing Letters, 8(1), 29-37. doi:10.1080/2150704x.2016.1233371

Batlle-Aguilar, J., Brovelli, A., Porporato, A., Barry, D.A. 2011. Modelling soil carbon and nitrogen cycles during land use change. A review. Agronomy for Sustainable Development. Vol. 31, No. 2, pp. 251-274.

Franko, U., Crocker, G.J., Grace, P.R., Klir, J., Korschens, M., Poulton, P.R., Richter, D.D. 1997. Simulating trends in soil organic carbon in long-term experiments using the CANDY model. Geoderma. Vol. 81, No. 1-2, pp. 109-120.

Huffman, T., Liu, J., McGovern, M., McConkey, B., Martin, T., 2015. Carbon stock and change from woody biomass on Canada's cropland between 1990 and 2000, Agriculture, Ecosystems \& Environment, 205, 102-111. https://doi.org/10.1016/j.agee.2014.10.009.

Hulley, G., Veraverbeke, S., Hook, S., 2014. Thermal-based techniques for land cover change detection using a new dynamic MODIS multispectral emissivity product (MOD21), Remote Sensing of Environment, 140, 755-765. https://doi.org/10.1016/j.rse.2013.10.014. 
IPCC. 2019. Climate Change and Land: An IPCC Special Report on climate change, desertification, land degradation, sustainable land management, food security and greenhouse gas fluxes in terrestrial ecosystems. https://www.google.com/url?sa=t\&rct=j\&q=\&esrc=s\&source= web\&cd=\&ved=2ahUKEwixv5GO4MPtAhWDW80KHW1oCt cQFjAAegQIBhAC\&url=https $\% 3 \mathrm{~A} \% 2 \mathrm{~F} \% 2 \mathrm{Fwww}$.ipcc.ch\%2Fs ite $\% 2$ Fassets $\% 2$ Fuploads $\% 2 F 2019 \% 2 F 08 \% 2 F 4 .-$

SPM_Approved_Microsite_FINAL.pdf\&usg=AOvVaw0kuYK b_g8YFTYyBmhRWkid

IPCC. 2003. Definitions and Methodological Options to Inventory Emissions from Direct Human-induced Degradation of Forests and Devegetation of Other Vegetation Types. Hayama, Japan, Institute for Global Environmental Strategies (IGES) for the Intergovernmental Panel on Climate Change

Ituen, I., Hu, B., 2021: An Automatic and Operational Method to Predict Landcover change using spatiotemporal MODIS data: A case study in Northern Ontario, Canada. ISPRS International Journal of Geo-Information (Under review)

Kurz, W.A., Dymond, C.C., White, T.M., Stinson, G., Shaw, C.H., Rampley, G.J., Smyth, C., Simpson, B.N., Neilson, E.T., Trofymow, J.A., Metsaranta, J., Apps, M.J., 2009. CBM-CFS3: A model of carbon-dynamics in forestry and land-use change implementing IPCC standards. Ecological Modelling. Vol. 220, No. 4, pp. 480-504.

Lemprière, T.C., Kurz, W.A., Hogg, E.H., Schmoll, C., Rampley, G.J., Yemshanov, D., McKenney, D.W., Gilsenan, R., Beatch, A., Blain, D., Bhatti, J.S., Krcmar, E. 2013. Canadian boreal forests and climate change mitigation. Environmental Reviews. Vol. 21, No. 4, pp. 293-321.

OMAFRA, 2017. Northern Ontario Agriculture Facts and Figures in Brief: http://www.omafra.gov.on.ca/english/livestock/beef/news/info_ vbn0713a4.htm (17 October 2017)

Seyum S., Taddese G., Mebrate T. Land use land cover changes on soil carbon stock in the Weshem Watershed, Ethiopia. Forest $\begin{array}{llll}\text { Res Eng Int J. 2019;3(1):24-30 DOI: } & \end{array}$ $\underline{10.15406 / \text { freij.2019.03.00074 }}$

Sharma, G., Sharma, L. K., \& Sharma, K. C. (2019). Assessment of land use change and its effect on soil carbon stock USING multitemporal satellite data in Semiarid region of Rajasthan, India. Ecological Processes, 8(1). doi:10.1186/s13717-0190193-5

Sleeter, B. M., Liu, J., Daniel, C., Rayfield, B., Sherba, J., Hawbaker, T. J., Zhu, Z., Selmants, P.C., \& Loveland, T. R. (2018). Effects of Contemporary land-use And Land-cover change on the Carbon balance of terrestrial ecosystems in the United States. Environmental Research Letters, 13(4), 045006. doi:10.1088/1748-9326/aab540

Tremblay S, Ouimet R. White Spruce Plantations on Abandoned Agricultural Land: Are They More Effective as C Sinks than Natural Succession? Forests. 2013; 4(4):1141-1157. https://doi.org/10.3390/f4041141

Veldkamp E. (1994) Organic carbontTurnover in three tropical soils underpasture after deforestation, Soil Sci. Soc. Am. J. 58, 175-180.
Webster, K.L., Beall, F.D., Creed, I.F., Kreutzweiser, D.P. 2015. Impacts and prognosis of natural resource development on water and wetlands in Canada's boreal zone. Environmental Reviews. Vol. 23, No. 1, pp. 78-131.

White, J. C., Wulder, M. A., Gómez, C., \& Stenhouse, G. (2011). A history of habitat DYNAMICS: Characterizing 35 years of Stand Replacing disturbance. Canadian Journal of Remote Sensing, 37(2), 234-251. doi:10.5589/m11-034 